\title{
Adaptive Neuro-Fuzzy Inference System (ANFIS) Model for Forecasting and Predicting Industrial Electricity Consumption in Nigeria
}

\author{
Sampson Sampson Uko, Ozuomba Simeon*, Ikpe Joseph Daniel \\ Department of Electrical/Electronic and Computer Engineering, University of Uyo, Nigeria
}

Received April 26, 2019; Revised August 30, 2019; Accepted September 6, 2019

\begin{abstract}
Copyright $(2019$ by authors, all rights reserved. Authors agree that this article remains permanently open access under
\end{abstract} the terms of the Creative Commons Attribution License 4.0 International License

\begin{abstract}
The main aim of this paper is to model the industrial power consumption in Nigeria with the Adaptive Neuro-Fuzzy Inference System (ANFIS) model and then forecast the industrial power consumed for the next five years beyond the available data. About 45 years (1970 to 2015) dataset was obtained from the Central Bank of Nigeria (CBN), the National Bureau of Statistics (NBS) and other relevant organizations. The data includes population, rainfall, electricity connectivity and temperature which are the explanatory variables. Matlab was used along with the dataset to train and evaluate the ANFIS model which was then used to forecast the industrial power consumption in Nigeria for the years 2016 to 2020.The prediction performance of the ANFIS model was compared to those of Autoregressive Moving Average model and Moving Average model. From the result obtained, ANFIS gave R-square value of 0.9977 (99.77\%), SSE value of 395.3674 and RMSE value of 2.9641 . The regression coefficient of $99.77 \%$ shows that about $99.77 \%$ of the variations in the industrial power consumption in Nigeria for the years 1970 to 2015 are explained by the selected explanatory variables. The forecast result showed that the Nigerian industrial power consumption would be about $374.7 \mathrm{MW}$ at the end of 2020 which is about $73.1 \%$ increase from the industrial power consumption in 2015 . As such, based on the industrial power consumption in 2015 , over $73 \%$ increment in power supply to the industrial sector will be required to satisfy the industrial sector's power demand in 2020.
\end{abstract}

Keywords Industrial Power Consumption, Adaptive Neuro-Fuzzy Inference System (ANFIS), Energy Forecast, Electricity Connectivity, Fuzzification, Membership Function

\section{Introduction}

Forecasting is the act of making prediction of future events and situations. In different areas of life, forecasting is the basic technique of decision making targeted at minimizing risk in decision making and reducing unanticipated cost $[1,2,3]$. Accordingly, in the power industry, correct prediction of future load demand enables power utility companies to supply electrical energy to the consumers economically. Particularly, it allows power utilities companies to plan their operations such as unit commitment and generator maintenance beforehand, and thus, serve their customers with more reliable and more economically efficient electric power $[4,5,6,7]$. This has become important seeing that energy resources are often limited along with challenges emanating from environmental factors [8, 9, 10, 11, 12]. Studies have shown that geographical location, population, social factors and weather factors have different impacts on power systems $[11,12,13,14,15,16]$. Therefore, accurate load forecasting model that takes into consideration the essential factors that do affect the power demand pattern is important in power system planning.

Consequently, in this paper Adaptive Neuro-Fuzzy Inference System (ANFIS) technique is used to model and forecast the industrial electricity consumption in Nigeria $[16,17,18,19,20]$. This has become necessary as Nigerian government is focused on diversifying its economy by facilitating more indigenous technologies, expanding its small and medium scale enterprises and attracts more foreign investments [21, 22, 23, 24, 25, 26]. ANFIS which is a kind of artificial neural network that is based on Takagi-Sugeno fuzzy inference system was developed in the early 1990s $[27,28,29,30,31,32,33]$. ANFIS integrates both neural networks and fuzzy logic principles and it has the potential to capture the benefits of both neural networks and fuzzy logic in a single framework [34, 35, 36, 37, 38]. 
One of the advantages of fuzzy systems is that they describe fuzzy rules, which fit the description of the real-world processes to a greater extent $[2,39,40,41,42$, $43,44]$. Another advantage of fuzzy systems is their interpretability; it means that it is possible to explain why a particular value appeared at the output of a fuzzy system. In view of its salient attributes, ANFIS has been employed in a number of studies including those concerning load forecasting [45, 46, 47, 48, 49].

\section{Methodology}

\subsection{Collection of Data}

In this paper Adaptive Neuro-Fuzzy Inference System (ANFIS) is used in modeling the industrial electricity consumption in Nigeria and then to forecast the industrial electricity consumption in Nigeria from 2016 to 2020.The 45 years (1970-2015) data used in the study was collected from various publications of the Central Bank of Nigeria $(\mathrm{CBN})$ and the National Bureau of Statistics (NBS). The data collected include: industrial electricity consumption, temperature, connectivity, population and rainfall. The data is given in Table 1 .

The raw data is normalized to within the range of 0.1 to 0.9 using the equation.

$$
x_{\text {norm }}=\frac{X}{X_{\max }}
$$

where $x_{\text {norm }}$ is the normalized data of the original values of the explanatory variables, $\mathrm{x}$ is the raw values of the explanatory variables (temperature, rainfall, population, connectivity and actual industrial electricity consumption). $X_{\max }$ is the maximum value of the explanatory variables (temperature, rainfall, population, connectivity and actual industrial power consumption). This normalized form is chosen because it tends to provide a better outcome on the Predicted Industrial Power Consumption (Predicted IPC). About 60 percent $(60 \%)$ of the original data was used as training dataset whereas 40 percent $(40 \%)$ of the dataset was used as the validation dataset. 
Table 1. Data from National Bureau of Statistics (NBS) and Central Bank of Nigeria (CBN)

\begin{tabular}{|c|c|c|c|c|c|}
\hline $\begin{array}{c}\text { Time } \\
\text { (years) }\end{array}$ & $\begin{array}{c}\text { Temperature } \\
\left({ }^{\circ} \mathrm{C}\right)\end{array}$ & Population & $\begin{array}{c}\text { Rainfall } \\
(\mathrm{mm})\end{array}$ & $\begin{array}{c}\text { Connectivity (\% of } \\
\text { population) }\end{array}$ & $\begin{array}{c}\text { Industrial Electricity Consumption } \\
(\mathrm{MW})\end{array}$ \\
\hline 1970 & 26.8690 & 56131844 & 93.2474 & 22 & 91.4000 \\
\hline 1971 & 26.4121 & 57453734 & 90.8679 & 22 & 114.9000 \\
\hline 1972 & 26.9176 & 58829319 & 87.6959 & 22 & 138.2000 \\
\hline 1973 & 27.2231 & 60285453 & 81.2038 & 22 & 146.1000 \\
\hline 1974 & 26.2714 & 61857023 & 94.4808 & 25 & 163.2000 \\
\hline 1975 & 26.2194 & 63565598 & 96.4250 & 25 & 200.4000 \\
\hline 1976 & 26.3880 & 65426976 & 91.4644 & 25 & 214.6000 \\
\hline 1977 & 26.4934 & 67425435 & 86.9932 & 25 & 253.0000 \\
\hline 1978 & 26.5287 & 69512233 & 101.4315 & 25 & 157.7000 \\
\hline 1979 & 26.9335 & 71619216 & 96.8826 & 30 & 160.3000 \\
\hline 1980 & 26.8761 & 73698096 & 100.0646 & 30 & 199.7000 \\
\hline 1981 & 26.7763 & 75729572 & 91.5726 & 30 & 121.0000 \\
\hline 1982 & 26.8601 & 77729802 & 85.6780 & 30 & 262.0000 \\
\hline 1983 & 27.0519 & 79729311 & 73.0148 & 30 & 254.4000 \\
\hline 1984 & 27.1845 & 81775215 & 89.0549 & 30 & 217.2000 \\
\hline 1985 & 26.9894 & 83901570 & 88.5841 & 30 & 259.8000 \\
\hline 1986 & 27.0078 & 86118043 & 88.4083 & 30 & 280.5000 \\
\hline 1987 & 27.5971 & 88412917 & 82.7691 & 30 & 294.1000 \\
\hline 1988 & 27.0661 & 90773613 & 94.7851 & 30 & 291.1000 \\
\hline 1989 & 26.4981 & 93179755 & 91.6024 & 30 & 257.9000 \\
\hline 1990 & 27.4483 & 95617345 & 89.0172 & 33 & 230.1000 \\
\hline 1991 & 27.0546 & 98085436 & 97.5072 & 33 & 253.7000 \\
\hline 1992 & 26.6130 & 100592458 & 90.8569 & 33 & 245.3000 \\
\hline 1993 & 27.0105 & 103145093 & 95.7557 & 33 & 237.4000 \\
\hline 1994 & 26.7261 & 105753088 & 97.6496 & 33 & 233.3000 \\
\hline 1995 & 27.1357 & 108424822 & 95.4165 & 35 & 218.7000 \\
\hline 1996 & 27.1161 & 111164651 & 101.9210 & 35 & 235.3000 \\
\hline 1997 & 27.0780 & 113975055 & 99.6741 & 35 & 236.8000 \\
\hline 1998 & 27.6369 & 116860691 & 96.2221 & 35 & 218.9000 \\
\hline 1999 & 27.0768 & 119826231 & 101.3462 & 35 & 191.8000 \\
\hline 2000 & 26.8463 & 122876723 & 93.7123 & 38 & 223.8000 \\
\hline 2001 & 26.9931 & 126014935 & 88.3470 & 38 & 241.9000 \\
\hline 2002 & 27.2266 & 129246283 & 90.4583 & 38 & 146.2000 \\
\hline 2003 & 27.3791 & 132581484 & 102.6651 & 40 & 196.0000 \\
\hline 2004 & 27.3415 & 136033321 & 96.4417 & 40 & 398.0000 \\
\hline 2005 & 27.4817 & 139611303 & 87.1168 & 40 & 182.3000 \\
\hline 2006 & 27.4051 & 143318011 & 95.9864 & 40 & 307.8320 \\
\hline 2007 & 27.4265 & 147152502 & 101.0405 & 41 & 296.3450 \\
\hline 2008 & 27.1349 & 151115683 & 109.3087 & 41 & 184.7520 \\
\hline 2009 & 27.8538 & 155207145 & 94.2806 & 41 & 230.9290 \\
\hline 2010 & 27.9143 & 159424742 & 94.9717 & 41 & 127.6150 \\
\hline 2011 & 29.6265 & 163770669 & 80.2430 & 42 & 150.6303 \\
\hline 2012 & 24.7959 & 168240403 & 101.8373 & 42 & 105.0084 \\
\hline 2013 & 24.0816 & 172816517 & 79.0466 & 42 & 166.1961 \\
\hline 2014 & 27.9760 & 177475986 & 114.1960 & 42 & 145.0290 \\
\hline 2015 & 26.9710 & 182201962 & 163.5670 & 43 & 216.4920 \\
\hline
\end{tabular}




\subsection{Development of the Adaptive Neuro-Fuzzy Inference System (ANFIS) Model}

Four unique inputs namely temperature, rainfall, population and electricity connectivity which were the explanatory variables were used in this work. Also, one output, the industrial power consumption was used in this work. The input data are converted to degrees of memberships and membership values in a process called fuzzification. The triangular membership function was used for the four inputs as well as the output. Each of the four inputs was divided into three triangular membership functions. Also, the output was divided into three triangular membership functions. The input variables (explanatory variables) and the output variables were imported to the ANFIS environment via the workspace key after clicking on load data. The outcome of these commands can be seen in Figure 1. Fuzzification process was performed in the MATLAB FIS editor and the outcome is given in Figure 2.The ANFIS structure is given in Figure 3 which shows the four input neurons with each neuron connected to three membership functions as it is also in the fuzzy part of the system. Membership function for each of the explanatory variables is shown in Figure 4 to Figure 7. The number of fuzzy logic rules used was two hundred and forty-six (246) as shown in Figure 8.

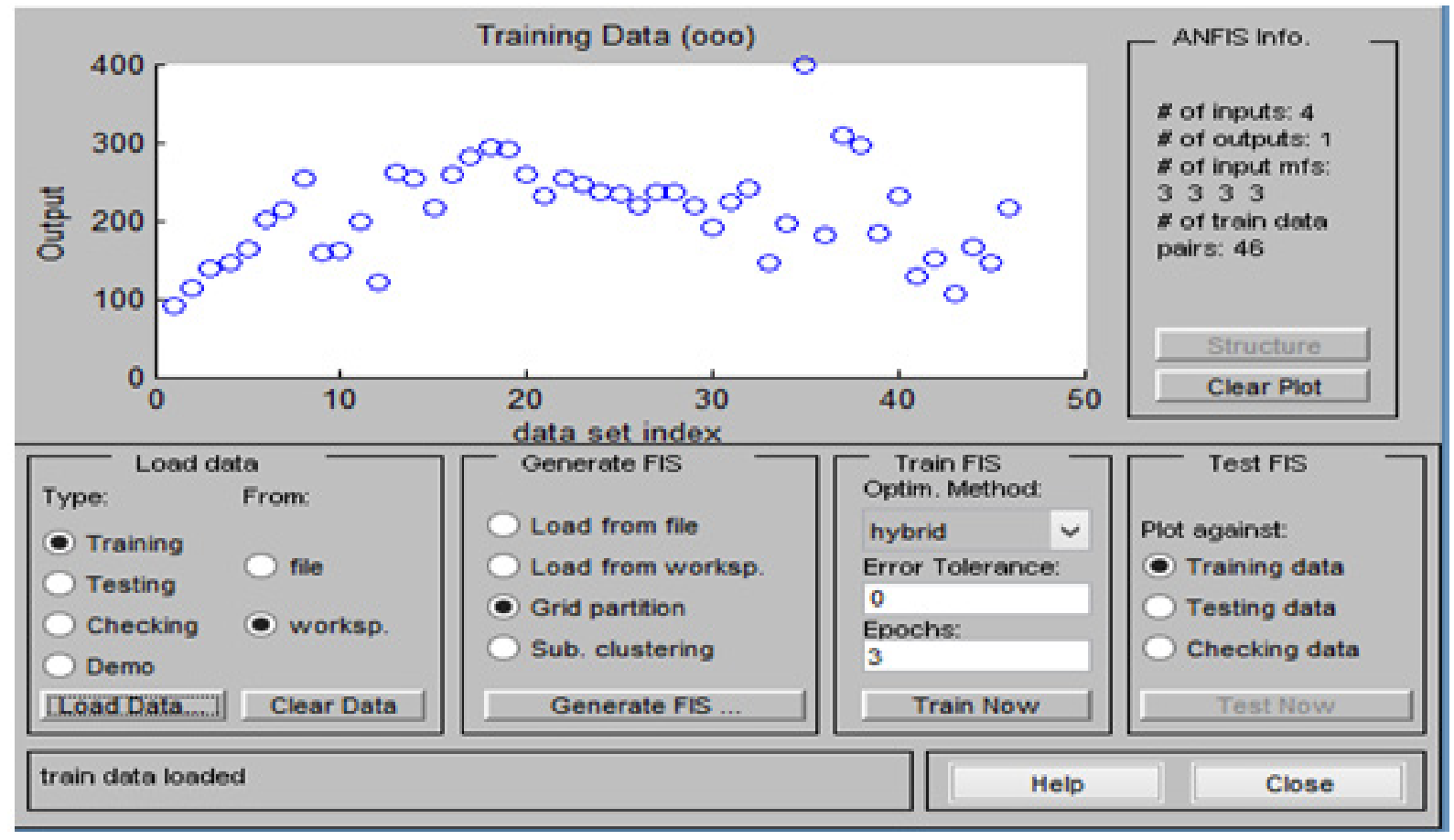

Figure 1. Graphic User Interface of ANFIS with input and output parameters

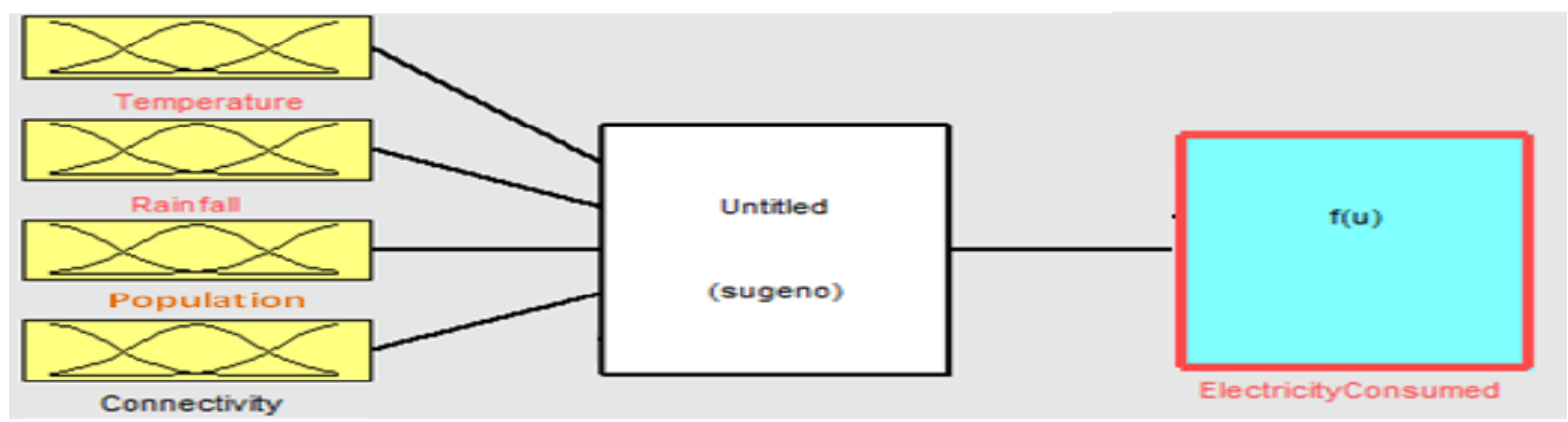

Figure 2. Graphic User Interface for fuzzy logic representation 


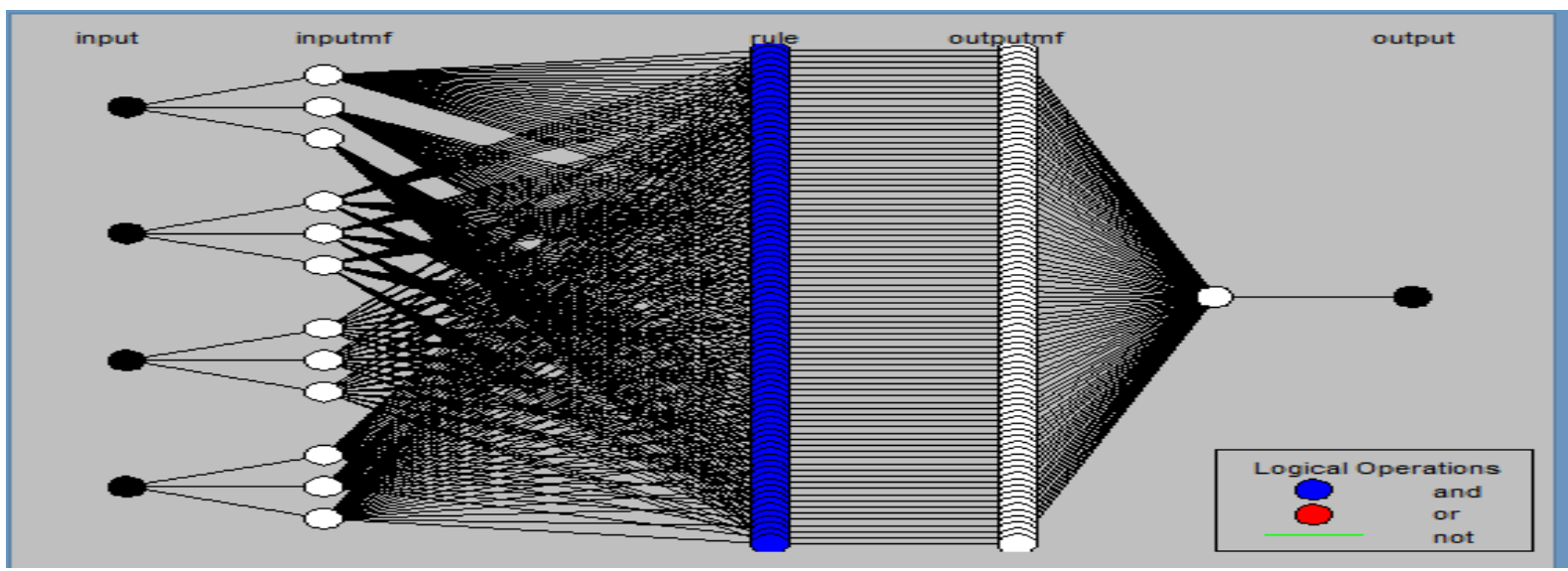

Figure 3. Graphic User Interface of the ANFIS model structure for industrial power consumption forecasting.

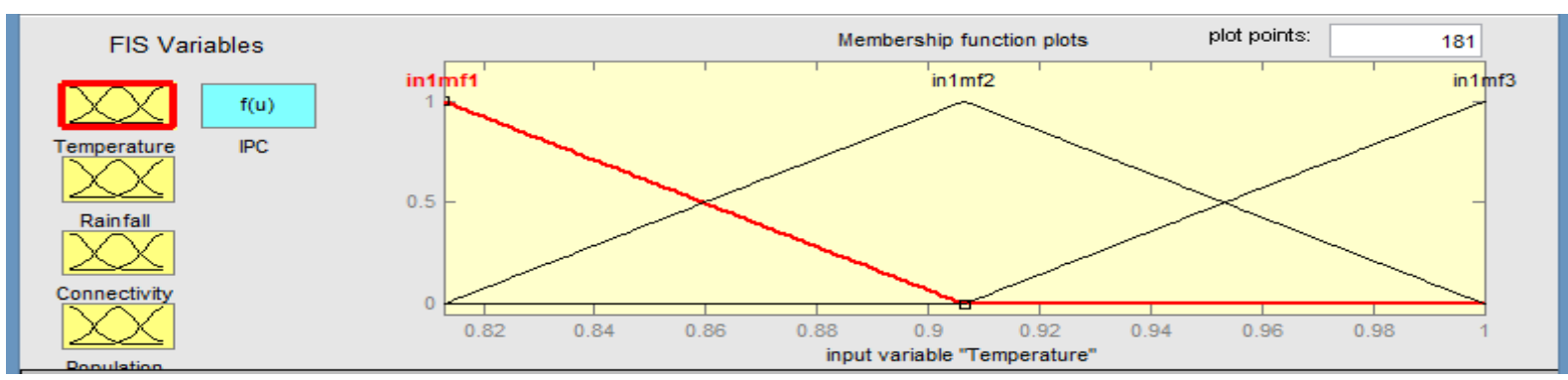

Figure 4. Membership function for the temperature variable.

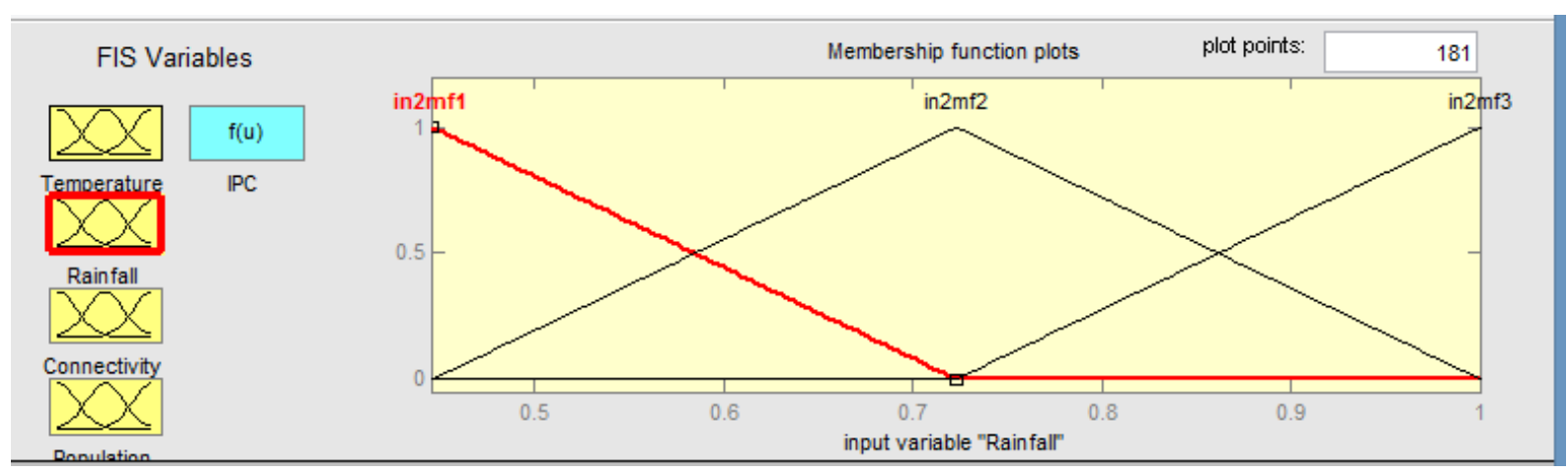

Figure 5. Membership function for the rainfall variable.

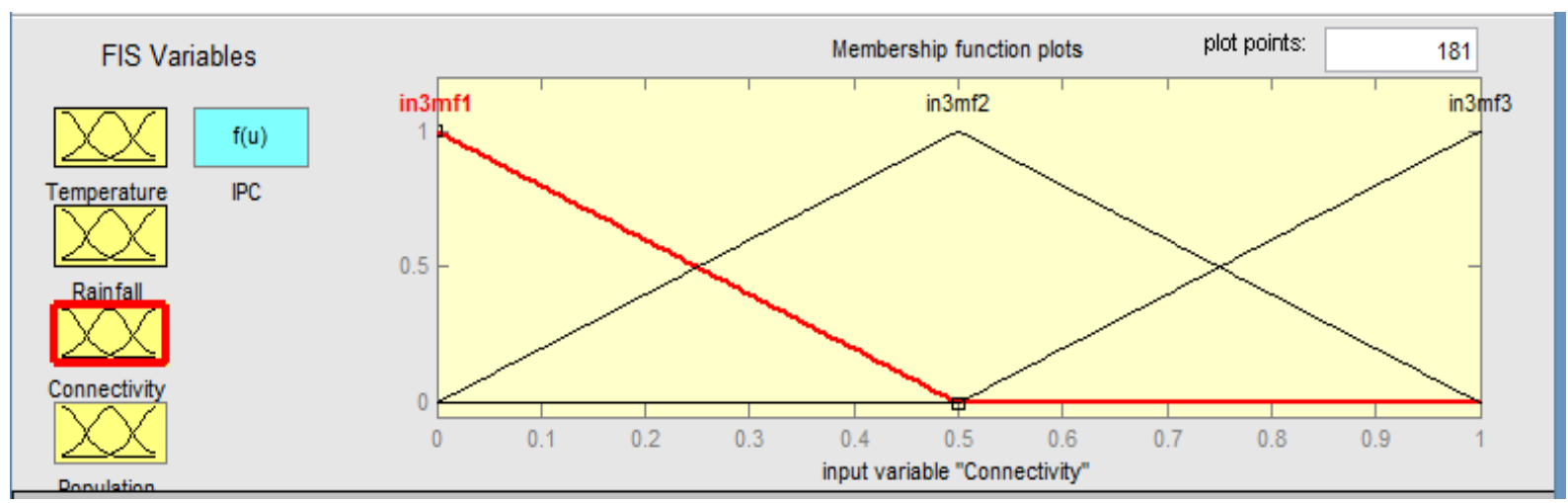

Figure 6. Membership function connectivity variable 


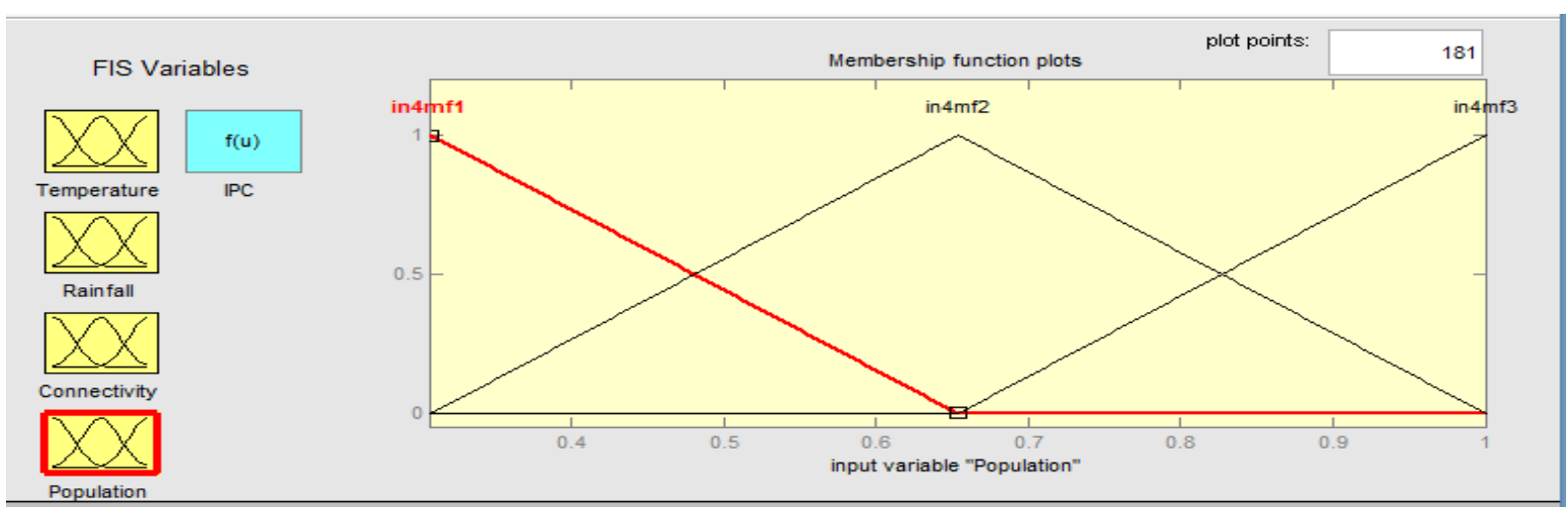

Figure 7. Membership function for population variable.

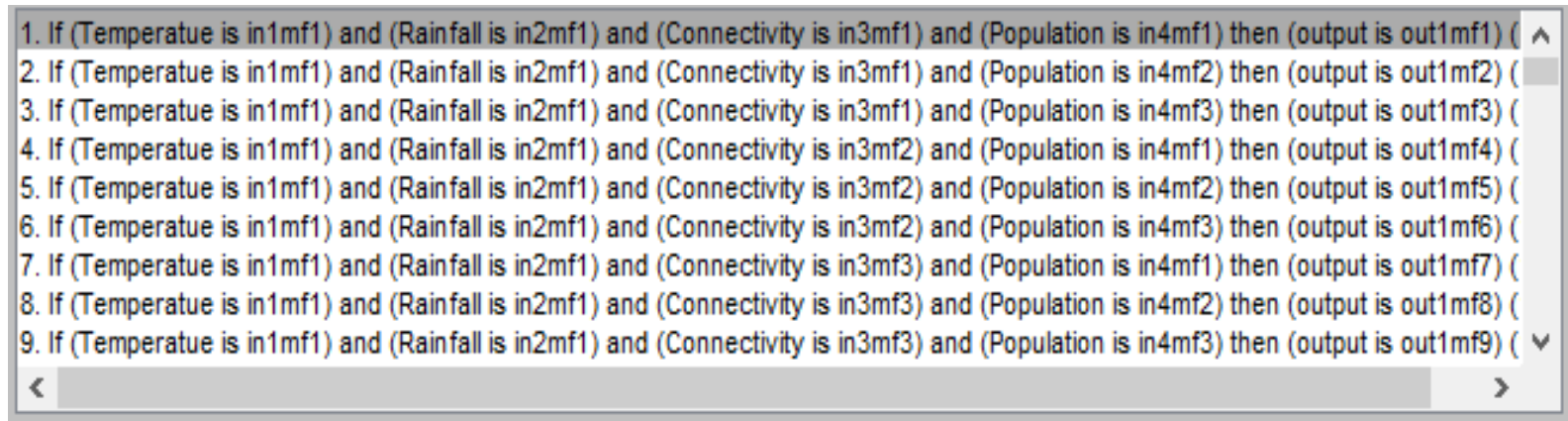

Figure 8. Fuzzy logic Rules

The ANFIS graphic user interface showing the error of the epoch is shown in Figure 9, while Figure 10 shows the checking of the ANIFIS predicted data. According to Figure 9, after simulating the system under 40 epochs (40 iterations), with the normalized dataset the error of the ANFIS system at the 40th iteration was 0.00076577 , after checking (Figure 10), the minimal error was 0.61265 . With this minimal error of 0.00076577 , it shows that the ANFIS can be used to effectively predict the industrial power consumption in Nigeria.

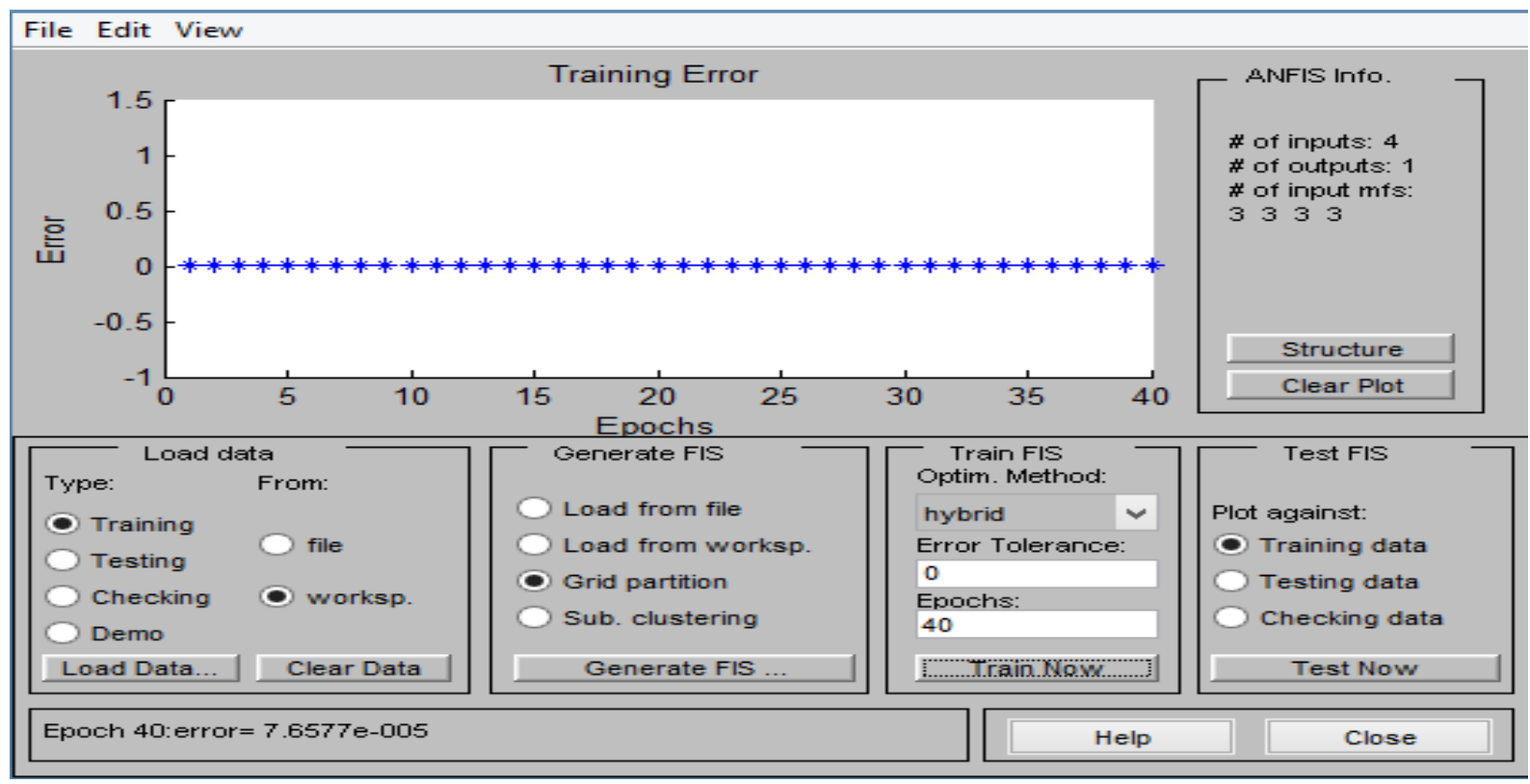

Figure 9. ANFIS Graphic User Interface showing the error of the epochs 


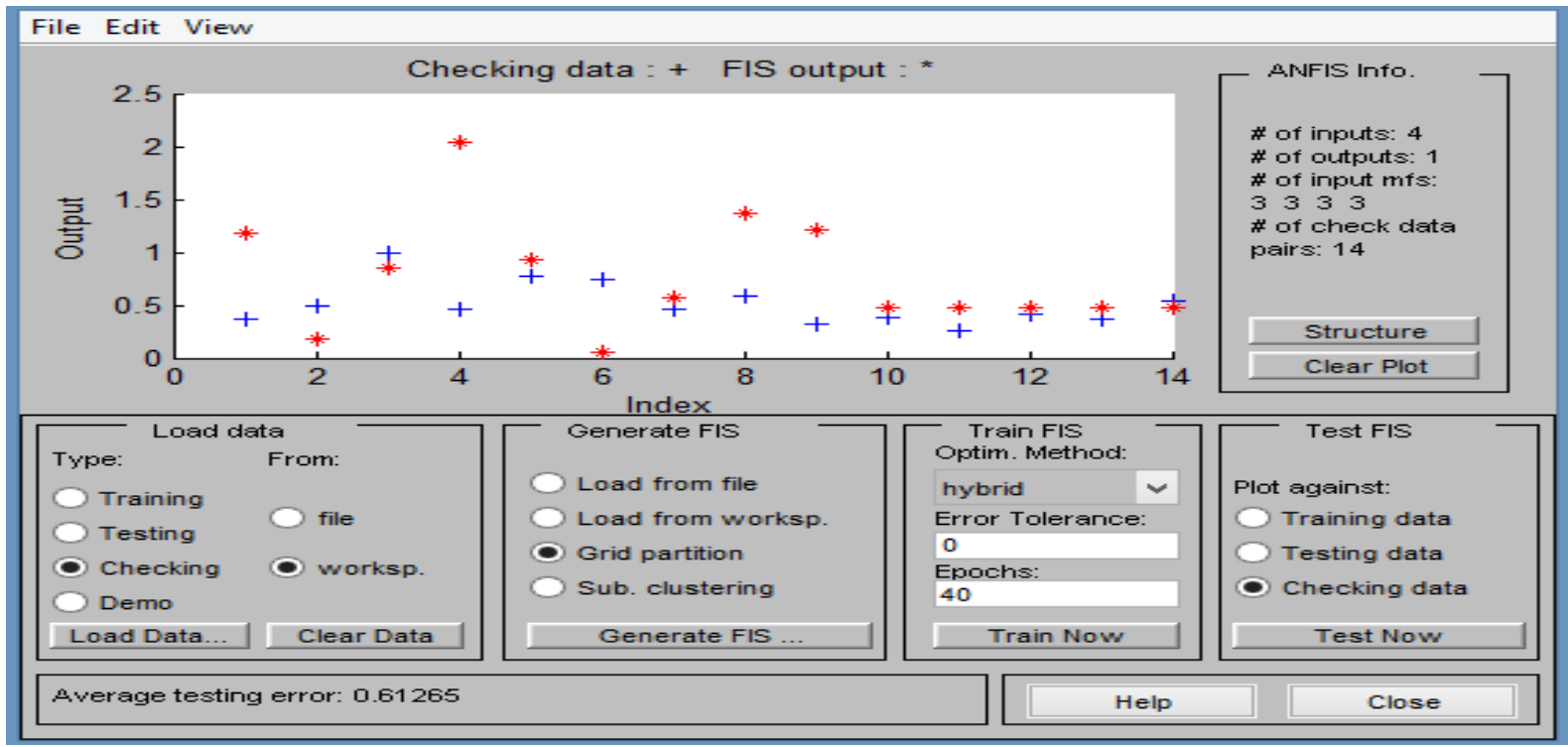

Figure 10. Checking of the ANFIS predicted data

The performance measures used to evaluate the developed model are the regression coefficient or coefficient of determination (R2), the root means square error (RMSE) and the sum of square errors (SSE). The Root Mean Square Error (RMSE) is given as follows;

$$
M S E=\frac{1}{n} \sum_{i=1}^{n}\left(Y_{t}-\hat{Y}_{t}\right)^{2}
$$

where: $Y_{t}$ is the actual industrial electricity consumption and $\hat{Y}_{t}$ is the predicted value from the model. The Root Means Square Error (RMSE) is given as;

The formula for the sum of square error (SSE) is given as;

$$
R M S E=\sqrt{\mathrm{MSE}}
$$

$$
S S E=\sum_{i=1}^{n}\left(Y_{t}-\hat{Y}_{t}\right)^{2}
$$

\subsection{Other Models Considered}

The prediction performance of the ANFIS model was compared to that of two other regression models namely, Autoregressive Moving Average Model and Moving Average Model. The models are developed from the same dataset used for the training of the ANFIS model. The autoregressive moving average model is expressed as follow;

$$
Y_{t}=-921.3945-0.8569 Y_{t-1}+247.9828 \varepsilon_{t-1}
$$

The moving average model is expressed as follows;

The moving average model for predicting industrial power consumption is given as:

$$
Y_{t}=-218.2246+81.3846 \varepsilon_{t-1}
$$

Where $\varepsilon_{t-1}$ is $\ln Y_{t-1}$

\section{Results and Discussions}

Table 2 shows the normalized data for the prediction of industrial electricity consumption in Nigeria with Adaptive-Neuro Fuzzy Inference System (ANFIS) model and the normalized ANFIS model predicted industrial power consumption in Nigeria for the years 1970 to 2015. Table 3 and Figure 11 show actual industrial power consumption in Nigeria (MW) and the ANFIS model predicted industrial power consumption in Nigeria for the years1970 to 2015.

Based on Table 3 and Figure 11, the regression coefficient between the actual industrial power consumed and the ANFIS model predicted industrial power consumed is 0.9977 (99.77\%), the SSE is 395.3674 and RMSE is 2.9641.The regression coefficient of $99.77 \%$ shows that about $99.77 \%$ of the variations in industrial power consumption in Nigeria for the years 1970 to 2015 are explained by the selected explanatory variables. 
Table2. Normalized data for the prediction of industrial electricity consumption in Nigeria with Adaptive-Neuro Fuzzy Inference System (ANFIS) model and the normalized ANFIS model predicted industrial power consumption in Nigeria for the years (1970 to 2015)

\begin{tabular}{|c|c|c|c|c|c|c|}
\hline $\begin{array}{l}\text { Time } \\
\text { (years) }\end{array}$ & $\begin{array}{l}\text { Normalized } \\
\text { Temperature }\end{array}$ & $\begin{array}{l}\text { Normalized } \\
\text { Population }\end{array}$ & $\begin{array}{c}\text { Normalized } \\
\text { Rainfall }\end{array}$ & $\begin{array}{l}\text { Normalized } \\
\text { Connectivity }\end{array}$ & $\begin{array}{c}\text { Normalized Actual } \\
\text { Industrial Electricity } \\
\text { Consumption }\end{array}$ & $\begin{array}{c}\text { Normalized Predicted } \\
\text { Industrial Power } \\
\text { Consumption }\end{array}$ \\
\hline 1970 & 0.9069 & 0.3081 & 0.5701 & 0.5116 & 0.2296 & 0.2302 \\
\hline 1971 & 0.8915 & 0.3153 & 0.5555 & 0.5116 & 0.2887 & 0.3140 \\
\hline 1972 & 0.9086 & 0.3229 & 0.5361 & 0.5116 & 0.3472 & 0.3458 \\
\hline 1973 & 0.9189 & 0.3309 & 0.4965 & 0.5116 & 0.3671 & 0.3670 \\
\hline 1974 & 0.8868 & 0.3395 & 0.5776 & 0.5814 & 0.4101 & 0.4145 \\
\hline 1975 & 0.8850 & 0.3489 & 0.5895 & 0.5814 & 0.5035 & 0.5076 \\
\hline 1976 & 0.8907 & 0.3591 & 0.5592 & 0.5814 & 0.5392 & 0.4758 \\
\hline 1977 & 0.8943 & 0.3701 & 0.5319 & 0.5814 & 0.6357 & 0.6422 \\
\hline 1978 & 0.8955 & 0.3815 & 0.6201 & 0.5814 & 0.3962 & 0.3966 \\
\hline 1979 & 0.9091 & 0.3931 & 0.5923 & 0.6977 & 0.4028 & 0.4330 \\
\hline 1980 & 0.9072 & 0.4045 & 0.6118 & 0.6977 & 0.5018 & 0.4555 \\
\hline 1981 & 0.9038 & 0.4156 & 0.5598 & 0.6977 & 0.3040 & 0.3793 \\
\hline 1982 & 0.9066 & 0.4266 & 0.5238 & 0.6977 & 0.6583 & 0.6106 \\
\hline 1983 & 0.9131 & 0.4376 & 0.4464 & 0.6977 & 0.6392 & 0.6340 \\
\hline 1984 & 0.9176 & 0.4488 & 0.5445 & 0.6977 & 0.5457 & 0.5447 \\
\hline 1985 & 0.9110 & 0.4605 & 0.5416 & 0.6977 & 0.6528 & 0.6622 \\
\hline 1986 & 0.9116 & 0.4727 & 0.5405 & 0.6977 & 0.7048 & 0.7109 \\
\hline 1987 & 0.9315 & 0.4852 & 0.5060 & 0.6977 & 0.7389 & 0.7399 \\
\hline 1988 & 0.9136 & 0.4982 & 0.5795 & 0.6977 & 0.7314 & 0.7192 \\
\hline 1989 & 0.8944 & 0.5114 & 0.5600 & 0.6977 & 0.6480 & 0.6896 \\
\hline 1990 & 0.9265 & 0.5248 & 0.5442 & 0.7674 & 0.5781 & 0.5752 \\
\hline 1991 & 0.9132 & 0.5383 & 0.5961 & 0.7674 & 0.6374 & 0.6125 \\
\hline 1992 & 0.8983 & 0.5521 & 0.5555 & 0.7674 & 0.6163 & 0.5867 \\
\hline 1993 & 0.9117 & 0.5661 & 0.5854 & 0.7674 & 0.5965 & 0.6349 \\
\hline 1994 & 0.9021 & 0.5804 & 0.5970 & 0.7674 & 0.5862 & 0.5791 \\
\hline 1995 & 0.9159 & 0.5951 & 0.5833 & 0.8140 & 0.5495 & 0.5517 \\
\hline 1996 & 0.9153 & 0.6101 & 0.6231 & 0.8140 & 0.5912 & 0.5948 \\
\hline 1997 & 0.9140 & 0.6255 & 0.6094 & 0.8140 & 0.5950 & 0.5851 \\
\hline 1998 & 0.9329 & 0.6414 & 0.5883 & 0.8140 & 0.5500 & 0.5515 \\
\hline 1999 & 0.9140 & 0.6577 & 0.6196 & 0.8140 & 0.4819 & 0.4838 \\
\hline 2000 & 0.9062 & 0.6744 & 0.5729 & 0.8837 & 0.5623 & 0.5624 \\
\hline 2001 & 0.9111 & 0.6916 & 0.5401 & 0.8837 & 0.6078 & 0.6104 \\
\hline 2002 & 0.9190 & 0.7094 & 0.5530 & 0.8837 & 0.3673 & 0.3605 \\
\hline 2003 & 0.9242 & 0.7277 & 0.6277 & 0.9302 & 0.4925 & 0.5007 \\
\hline 2004 & 0.9229 & 0.7466 & 0.5896 & 0.9302 & 1.0000 & 0.9863 \\
\hline 2005 & 0.9276 & 0.7662 & 0.5326 & 0.9302 & 0.4580 & 0.4683 \\
\hline 2006 & 0.9250 & 0.7866 & 0.5868 & 0.9302 & 0.7734 & 0.7777 \\
\hline 2007 & 0.9258 & 0.8076 & 0.6177 & 0.9535 & 0.7446 & 0.7465 \\
\hline 2008 & 0.9159 & 0.8294 & 0.6683 & 0.9535 & 0.4642 & 0.4641 \\
\hline 2009 & 0.9402 & 0.8518 & 0.5764 & 0.9535 & 0.5802 & 0.5593 \\
\hline 2010 & 0.9422 & 0.8750 & 0.5806 & 0.9535 & 0.3206 & 0.3334 \\
\hline 2011 & 1.0000 & 0.8988 & 0.4906 & 0.9767 & 0.3785 & 0.3790 \\
\hline 2012 & 0.8370 & 0.9234 & 0.6226 & 0.9767 & 0.2638 & 0.2638 \\
\hline 2013 & 0.8129 & 0.9485 & 0.4833 & 0.9767 & 0.4176 & 0.4176 \\
\hline 2014 & 0.9443 & 0.9741 & 0.6982 & 0.9767 & 0.3644 & 0.3649 \\
\hline 2015 & 0.9104 & 1.0000 & 1.0000 & 1.0000 & 0.5439 & 0.5439 \\
\hline
\end{tabular}


Table 3. The actual industrial power consumption in Nigeria (MW) and the ANFIS model predicted industrial power consumption in Nigeria for the years 1970 to 2015

\begin{tabular}{|c|c|c|}
\hline $\begin{array}{c}\text { Time } \\
\text { (years) }\end{array}$ & $\begin{array}{l}\text { Actual Industrial Electricity Consumption in Nigeria } \\
\text { (MW ) }\end{array}$ & $\begin{array}{l}\text { Predicted Industrial Power Consumption (MW ) in Nigeria } \\
\text { (MW) }\end{array}$ \\
\hline 1970 & 91.4 & 91.6 \\
\hline 1971 & 114.9 & 125.0 \\
\hline 1972 & 138.2 & 137.6 \\
\hline 1973 & 146.1 & 146.1 \\
\hline 1974 & 163.2 & 165.0 \\
\hline 1975 & 200.4 & 202.0 \\
\hline 1976 & 214.6 & 189.4 \\
\hline 1977 & 253.0 & 255.6 \\
\hline 1978 & 157.7 & 157.8 \\
\hline 1979 & 160.3 & 172.3 \\
\hline 1980 & 199.7 & 181.3 \\
\hline 1981 & 121.0 & 151.0 \\
\hline 1982 & 262.0 & 243.0 \\
\hline 1983 & 254.4 & 252.3 \\
\hline 1984 & 217.2 & 216.8 \\
\hline 1985 & 259.8 & 263.6 \\
\hline 1986 & 280.5 & 282.9 \\
\hline 1987 & 294.1 & 294.5 \\
\hline 1988 & 291.1 & 286.2 \\
\hline 1989 & 257.9 & 274.5 \\
\hline 1990 & 230.1 & 228.9 \\
\hline 1991 & 253.7 & 243.8 \\
\hline 1992 & 245.3 & 233.5 \\
\hline 1993 & 237.4 & 252.7 \\
\hline 1994 & 233.3 & 230.5 \\
\hline 1995 & 218.7 & 219.6 \\
\hline 1996 & 235.3 & 236.7 \\
\hline 1997 & 236.8 & 232.9 \\
\hline 1998 & 218.9 & 219.5 \\
\hline 1999 & 191.8 & 192.6 \\
\hline 2000 & 223.8 & 223.8 \\
\hline 2001 & 241.9 & 242.9 \\
\hline 2002 & 146.2 & 143.5 \\
\hline 2003 & 196.0 & 199.3 \\
\hline 2004 & 398.0 & 392.5 \\
\hline 2005 & 182.3 & 186.4 \\
\hline 2006 & 307.8 & 309.5 \\
\hline 2007 & 296.3 & 297.1 \\
\hline 2008 & 184.8 & 184.7 \\
\hline 2009 & 230.9 & 222.6 \\
\hline 2010 & 127.6 & 132.7 \\
\hline 2011 & 150.6 & 150.8 \\
\hline 2012 & 105.0 & 105.0 \\
\hline 2013 & 166.2 & 166.2 \\
\hline 2014 & 145.0 & 145.2 \\
\hline 2015 & 216.5 & 216.5 \\
\hline
\end{tabular}




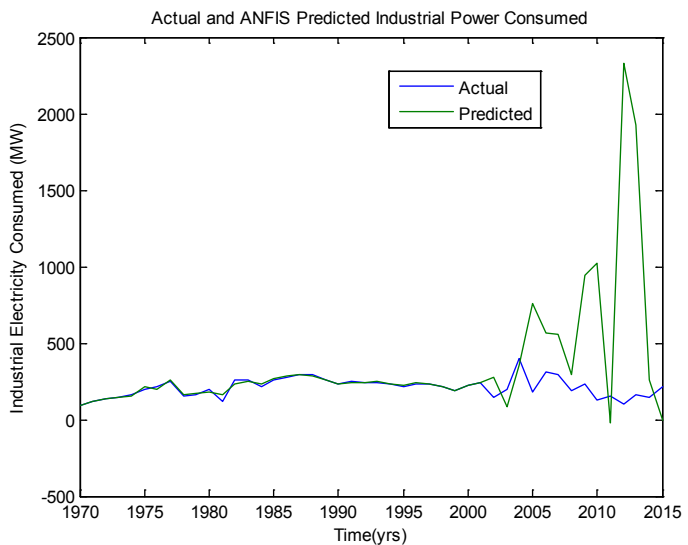

Figure 11. Comparison of the actual industrial power consumed and ANFIS model predicted industrial power consumed in Nigeria for the years 1970 to 2015

The comparison of the actual industrial power consumed with the Autoregressive moving average model predicted industrial power is shown in Figure 12. Also, the comparison of the actual industrial power consumed with the moving average model predicted industrial power is shown in Figure 13. The prediction performance of the three models considered in this paper is shown in Table 4. The results in Table 4 show that among the three models the ANFIS model has the best prediction performance. In this study, the ANFIS model was developed (trained) using $60 \%$ of the dataset which consist of the data from 1970 to 2001. Also, the ANFIS model was validated using 40\% of the dataset which consist of the data from 2002 to 2015. Again, Table 4 shows that the prediction performance of the ANFIS model with respect to the training data and also with respect to the validation data are very good. As such, the ANFI model was used to forecast the industrial electricity consumption in Nigeria from 2016 to 2020. The ANFIS forecast result is shown in Figure 14 and Table 5. From Figure 14, Nigeria shall witness the least industrial power consumption in October of 2017 with a total industrial power consumption of about 323.2 MW. The Nigerian industrial power consumption will be about $374.7 \mathrm{MW}$ at the end of 2020 . This is about $73.1 \%$ increase from the industrial power consumption in 2015 . As such, based on the last published industrial power consumption in 2015 , over $73 \%$ increment in power supply to the industrial sector will be required to satisfy the industrial sector's power demand in 2020.
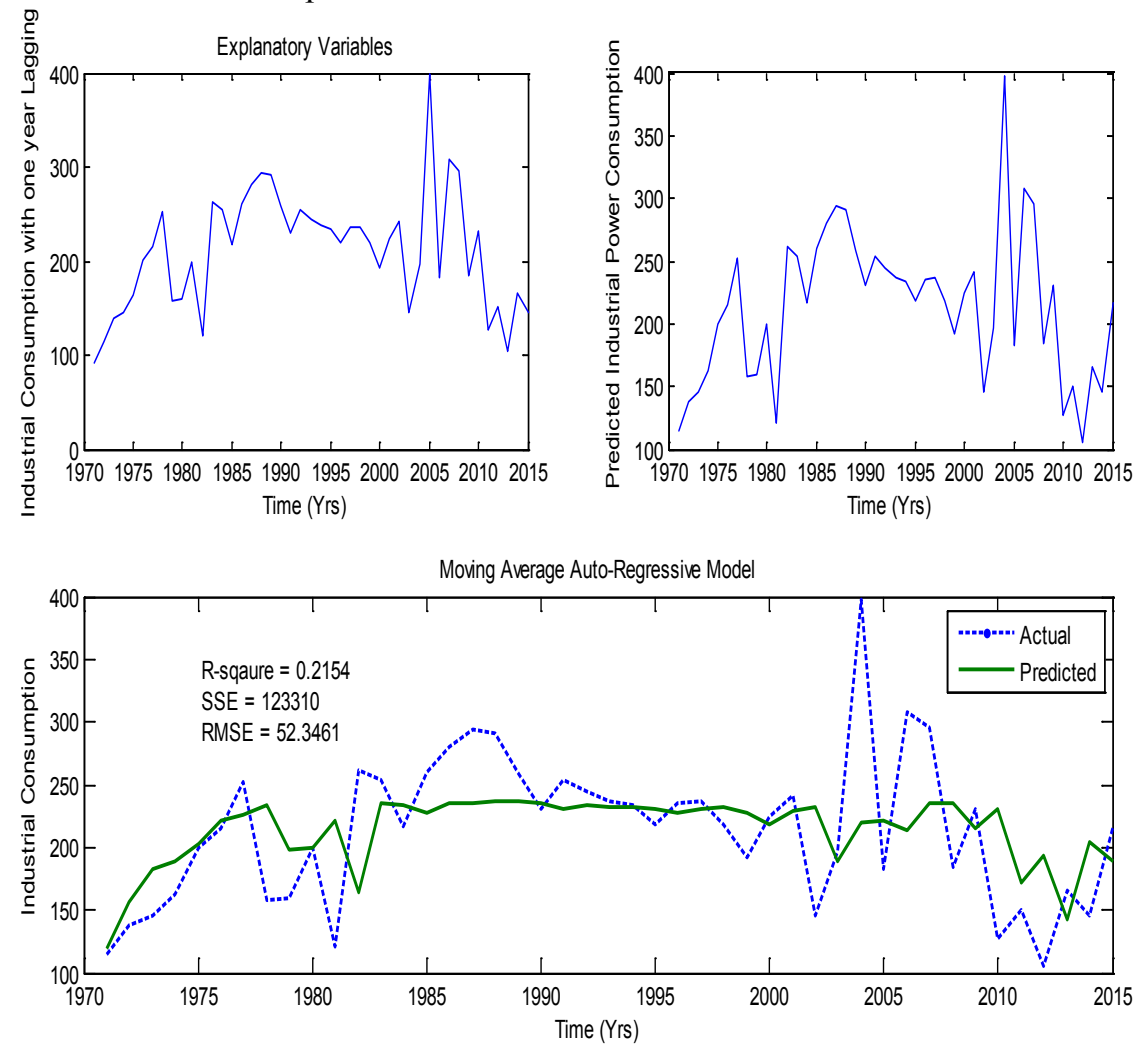

Figure 12. Comparison of the actual industrial power consumed with Autoregressive 

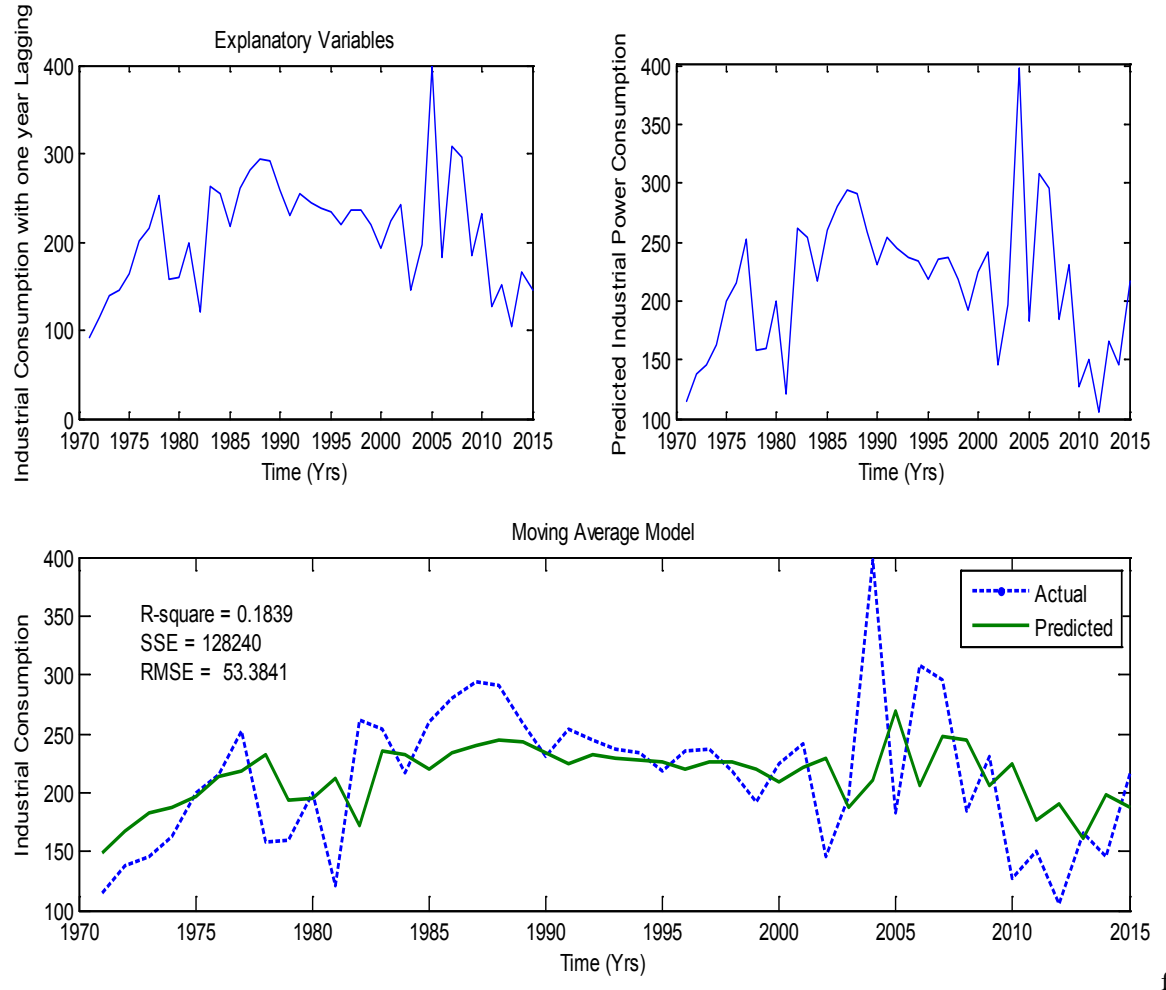

Figure 13. Comparison of the actual industrial power consumed with moving average model predicted industrial power consumed

Table 4. Prediction performance of the three models along with the ANFIS performance based on the training and validation datasets

\begin{tabular}{|c|c|c|c|}
\hline Models & R-Square & SSE & RMSE \\
\hline Auto-Regressive (1970 -2015 dataset) & $0.1485(14.85 \%)$ & 133820 & 54.5322 \\
\hline Moving Average(1970 -2015 dataset) & $0.1839(18.39 \%)$ & 128240 & 53.3841 \\
\hline ANFIS (1970 -2015 dataset) & $0.9977(99.77 \%)$ & 395.3674 & 2.9641 \\
\hline ANFIS Training Data (1970 -2001 dataset) & $0.9992(99.92 \%)$ & 395.3674 & 2.4225 \\
\hline ANFIS Validation (2002 -2015 dataset) & $0.9974(99.74 \%)$ & 395.3674 & 3.1613 \\
\hline
\end{tabular}

Table 5. The five years forecast of the industrial power consumption in Nigeria using ANFIS model

\begin{tabular}{|c|c|c|c|c|c|}
\hline Time (Years) & Temperature $\left({ }^{\circ} \mathrm{C}\right)$ & Rainfall $(\mathrm{mm})$ & Population & Connectivity $(\%)$ & Forecasted Industrial Power consumed (MW) \\
\hline 2016 & 26.8210 & 96.0532 & 185330100 & 41.0 & 391.0 \\
\hline 2017 & 27.3320 & 102.4870 & 188219552 & 42.0 & 339.5 \\
\hline 2018 & 27.1920 & 88.3310 & 191233001 & 44.0 & 323.2 \\
\hline 2019 & 28.1390 & 109.8310 & 193154212 & 43.0 & 377.0 \\
\hline 2020 & 27.1330 & 90.6190 & 196017022 & 41.5 & 374.7 \\
\hline
\end{tabular}




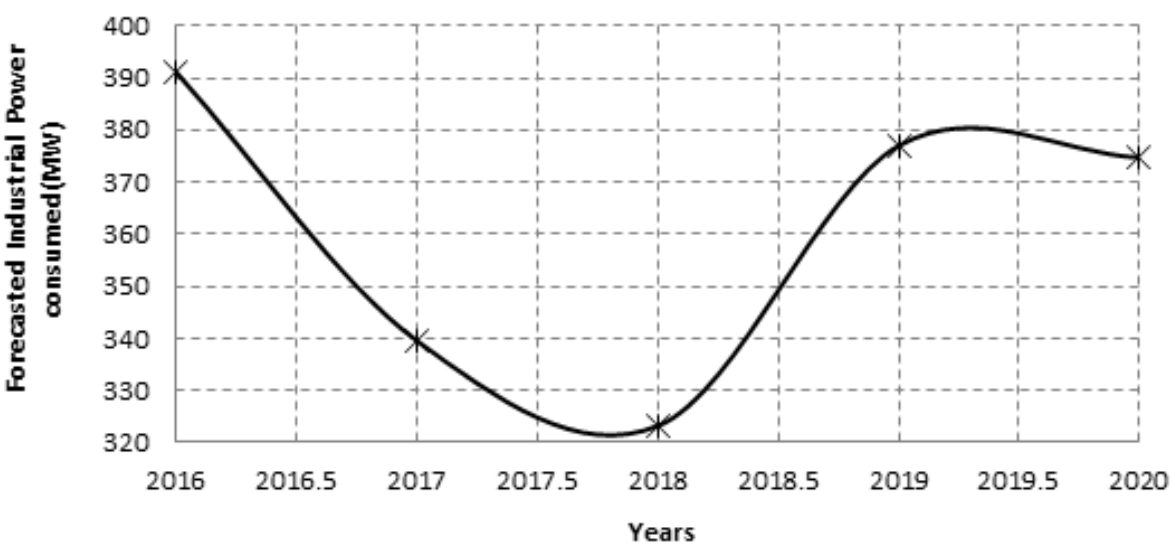

Figure 14. Forecast of Industrial Power Consumption in Nigeria for five years (2016 to 2020) with ANFIS model

\section{Conclusions}

Development and evaluation of Adaptive Neuro-Fuzzy Inference System (ANFIS) model for characterizing the industrial power consumption in Nigeria is presented. About 45 years data on industrial power consumption in Nigeria, population, rainfall, electricity connectivity and temperature was obtained relevant organisations where population, rainfall, electricity connectivity and temperature are the explanatory variables. Matlab was used along with the dataset to train and evaluate the ANFIS model which was then used to forecast the industrial power consumption in Nigeria for the years 2016 to 2020.The prediction performance of the ANFIS model was compared to those of Autoregressive Moving Average Model and Moving Average Model. In all the results obtained, ANFIS gave very high and acceptable R-square value which showed that about $99.77 \%$ of the variations in industrial power consumption in Nigeria for the years 1970 to 2015 are explained by the selected explanatory variables. The forecast result showed that based on the industrial power consumption in 2015 , over $73 \%$ increment in power supply to the industrial sector will be required to satisfy the industrial sector's power demand in 2020.

\section{REFERENCES}

[1] Dong, X., Lu, H., Xia, Y., \&Xiong, Z. (2016). Decision-Making Model under Risk Assessment Based on Entropy. Entropy, 18(11), 404.

[2] Ghore, S., \& Goswami, A. (2015) Short Term Load Forecasting of Chhattisgarh Grid Using Adaptive Neuro Fuzzy Inference System.International Journal of Science and Research (IJSR) Volume 4 Issue 11, November 2015

[3] Amlabu, C. A., Agber, J. U., Onah, C. O., \& Mohammed, S. Y. (2013). Electric Load Forecasting: A Case Study of the Nogerian Power Sector. International Journal of Engineering and Innovative Technology, 2, 23-27.
[4] Awosope, C. (2015). Nigeria Electricity Industry: Issues, Challenges and Solutions.

[5] Paaso, E. A., \& Liao, Y. (2013). Development of New Algorithms for Power System Short-Term Load Forecasting. Development, 2(02).

[6] Baharudin, Z., \& Kamel, N. (2008, December). Autoregressive method in short term load forecast. In Power and Energy Conference, 2008. PECon 2008. IEEE 2nd International (pp. 1603-1608). IEEE.

[7] Burns, S., \& Gross, G. (1990). Value of service reliability. IEEE Transactions on Power Systems, 5(3), 825-834.

[8] Timmons, D., Harris, J. M., \& Roach, B. (2014). The economics of renewable energy. Global Development and Environment Institute, Tufts University, 52.

[9] Majano, A. M. (2014). Study on the development of the renewable energy Market in Latin America and the Caribbean. Inter-American Development Bank.

[10] Hughes, B. B., Irfan, M. T., Moyer, J. D., Rothman, D. S., \& Solórzano, J. R. (2012). Exploring future impacts of environmental constraints on human development. Sustainability, 4(5), 958-994.

[11] Enete, A. A., \& Amusa, T. A. (2010). Challenges of agricultural adaptation to climate change in Nigeria: A synthesis from the literature. Field Actions Science Reports. The Journal of Field Actions, 4.

[12] Riddell, A., Ronson, S., Counts, G., \& Spenser, K. (2004). Towards sustainable energy: the current fossil fuel problem and the prospects of geothermal and nuclear power. Journal on trade \& environment.-Stanford University, California, USA.

[13] Wu, X., Lu, Y., Zhou, S., Chen, L., \&Xu, B. (2016). Impact of climate change on human infectious diseases: Empirical evidence and human adaptation. Environment international, $86,14-23$.

[14] Akanni, P. O., Oke, A. E., \& Akpomiemie, O. A. (2015). Impact of environmental factors on building project performance in Delta State, Nigeria. HBRC Journal, 11(1), 91-97.

[15] Damalas, C. A., \& Eleftherohorinos, I. G. (2011). Pesticide exposure, safety issues, and risk assessment indicators. 
International journal of environmental research and public health, 8(5), 1402-1419.

[16] Evans, R. G., \& Sadler, E. J. (2008). Methods and technologies to improve efficiency of water use. Water resources research, 44(7).

[17] Patz, J. A., Githeko, A. K., McCarty, J. P., Hussein, S., Confalonieri, U., \& De Wet, N. (2003). Climate change and infectious diseases. Climate change and human health: risks and responses, 6, 103-37.

[18] Saravanan, S., Kannan, S., \& Thangaraj, C. (2015). Prediction of India's Industrial Sector Electricity Consumption Using ANFIS. In Power Electronics and Renewable Energy Systems (pp. 1281-1288). Springer, New Delhi.

[19] Mamlook, R., Badran, O., \& Abdulhadi, E. (2009). A fuzzy inference model for short-term load forecasting. Energy Policy, 37(4), 1239-1248.

[20] Ying, L. C., \& Pan, M. C. (2008). Using adaptive network based fuzzy inference system to forecast regional electricity loads. Energy Conversion and Management, 49(2), 205-211.

[21] Adeoye, A. A. (2015). The effect of entrepreneurship on economy growth and development in Nigeria. International journal of development and economic sustainability, 3(2), 49-65.

[22] Chete, L. N., Adeoti, J. O., Adeyinka, F. M., \& Ogundele, O (2014). Industrial development and growth in Nigeria: Lessons and challenges (No. 2014/019). WIDER Working Paper.

[23] Ogechukwu, A. D., \& Oboreh, J. S. (2013). Small and medium scale enterprises (SMEs) in Nigeria the marketing interface. Global Journal of Management and Business Research.

[24] Atawodi, O. W., \& Ojeka, S. A. (2012). Relationship between tax policy, growth of SMEs and the Nigerian economy. International Journal of Business and Management, 7(13), 125.

[25] Iwuagwu, O. (2011). The cluster concept: Will Nigeria's new industrial development strategy jumpstart the country's industrial takeoff. Afro Asian Journal of Social Sciences, 2(2.4), 1-24.

[26] ECONOMY, I. A. G. (2004, June). Promoting SMEs for Development. In 2 nd OECD Conference of Ministers Responsible for Small and Medium Sized Enterprises (SMEs) (pp. 3-5).

[27] Garg, V., Singh, V. P., \& Raj, V. (Eds.). (2017). Development of Water Resources in India (Vol. 75). Springer.

[28] Lee, H., Shin, G., Hong, S., Choi, J., \& Chun, M. (2016). Post-Chlorination Process Control based on Flow Prediction by Time Series Neural Network in Water Treatment Plant. International Journal of Fuzzy Logic and Intelligent Systems, 16(3), 197-207.

[29] Jaiswal, G. P., \& Giri, R. N. (2015). Software Reliability Estimation of Component based Software System using Fuzzy Logic. International Journal of Computer Science and Information Security, 13(7), 66.
[30] Kokkinos, K., Loukas, A., \& Samaras, N. (2015). DEVELOPMENT AND EVALUATION OF AN ADAPTIVE NEURO FUZZY INFERENCE SYSTEM FOR THE CALCULATION OF SOIL WATER RECHARGE IN A WATERSHED. European Scientific Journal, ESJ, 11(10).

[31] Xie, H. B., Guo, T., Bai, S., \&Dokos, S. (2014). Hybrid soft computing systems for electromyographic signals analysis: a review. Biomedical engineering online, 13(1), 8.

[32] Nauck, D. D., \& Nürnberger, A. (2013). Neuro-fuzzy systems: A short historical review. Computational Intelligence in Intelligent Data Analysis, (445), 91-109.

[33] Güler, I., \&Übeyli, E. D. (2005). Adaptive neuro-fuzzy inference system for classification of EEG signals using wavelet coefficients. Journal of neuroscience methods, 148(2), 113-121.

[34] Atia, D. M., \& El-madany, H. T. (2017). Analysis and design of greenhouse temperature control using adaptive neuro-fuzzy inference system. Journal of Electrical Systems and Information Technology, 4(1), 34-48.

[35] Saghati, A. H., Zadkarim, S., \& Emari, H. (2016). Employee Commitment Prediction in Civil Projects Using Adaptive Neuro-Fuzzy Inference System. Journal of Current Research in Science, (2), 326.

[36] Al Maliky, S., \& Sattar, B. (Eds.). (2014). Multidisciplinary perspectives in cryptology and information security. IGI Global.

[37] Tahmasebi, P., \& Hezarkhani, A. (2012). A hybrid neural networks-fuzzy logic-genetic algorithm for grade estimation. Computers \& geosciences, 42, 18-27.

[38] Kothari, C. R. (2004). Research methodology: Methods and techniques. New Age International.

[39] Kabir, G., \& Hasin, M. A. A. (2014). Application of adaptive neuro fuzzy inference system in demand forecasting for power engineering company. International Journal of Industrial and Systems Engineering, 18(2), 237-255.

[40] DC-DC, P. O. N. I. (2011) TO MINIMIZE CURRENT DISTRIBUTION ERROR (CDE) IN PARALLEL OF NON IDENTIC DC-DC CONVERTERS USING ADAPTIVE NEURO FUZZY INFERENCE SYSTEM. Journal of theoretical and applied information technology Volume 25 no 1.

[41] Azar, A. T. (2010). Adaptive neuro-fuzzy systems. Fuzzy Systems. Vienna, Austria: IN-TECH, 10, 7220.

[42] Lim, E. A., \& Jayakumar, Y. (2008). A study of neuro-fuzzy system in approximation-based problems. Matematika, 24, 113-130.

[43] Albertos, P., \&Sala, A. (1998, September). Fuzzy logic controllers. Advantages and drawbacks. In VIII International Congress of Automatic Control (Vol. 3, pp. 833-844).

[44] Passino, K. M., Yurkovich, S., \& Reinfrank, M. (1998). Fuzzy control (Vol. 20). Reading, MA: Addison-wesley.

[45] Santika, G. D., Mahmudy, W. F., \& Naba, A. (2017). Electrical Load Forecasting using Adaptive Neuro-Fuzzy 
Inference System. Int. J. Advance Soft Compu. Appl, 9(1).

[46] Pal, S., \& Sharma, A. K. (2015). Short-Term Load Forecasting Using Adaptive Neuro-Fuzzy Inference System (ANFIS). Int. Journal of Novel Research in Electrical and Mechanical Engineering, 2(2), 65-71.

[47] Bigdeli, N., Afshar, K., Gazafroudi, A. S., \& Ramandi, M. Y. (2013). A comparative study of optimal hybrid methods for wind power prediction in wind farm of Alberta, Canada. Renewable and sustainable energy reviews, 27, 20-29.

[48] Xia, J., Zhao, P., \& Dai, Y. (2010, October). Neuro-fuzzy networks for short-term wind power forecasting. In Power System Technology (POWERCON), 2010 International Conference on (pp. 1-5). IEEE.

[49] Johnson, P. L., Negnevitsky, M., \& Muttaqi, K. M. (2007, December). Short term wind power forecasting using adaptive neuro-fuzzy inference systems. In Power Engineering Conference, 2007. AUPEC 2007. Australasian Universities (pp. 1-6). IEEE. 